
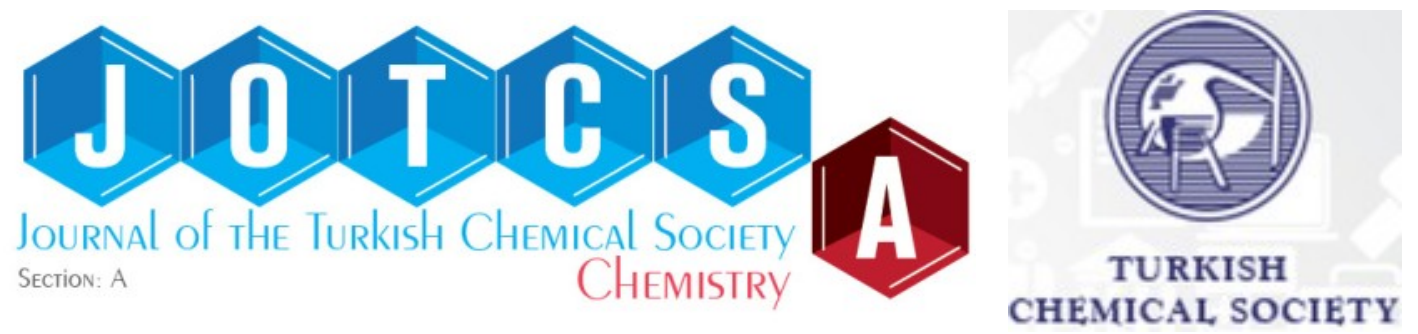

\title{
Effect of o-MMT Content on Properties of Poly (vinyl chloride)/Poly (acrylonitrile styrene acrylate) Blends
}

\author{
Yunus Emre Kökçan ${ }^{1}$ 过, Yasemin $\operatorname{Tamer}^{1 *}$ QD \\ ${ }^{1}$ Department of Polymer Materials Engineering, Faculty of Engineering, Yalova University, 77100, Yalova, \\ Turkey
}

\begin{abstract}
In this study, poly(vinyl chloride) (PVC)/poly(acrylonitrile styrene acrylate) (ASA)/ organophilic montmorillonite (O-MMT) nanocomposites were prepared and the effects of o-MMT content on the properties of PVC/ASA blends were investigated. The thermal stability, mechanical properties and water absorption percentages of the nanocomposites were studied. Surface morphology studies of the o-MMT containing blends were also performed using scanning electron microscopy (SEM). Thermogravimetric analysis (TGA) test results showed that o-MMT inclusion enhanced the thermal stability of PVC/ASA/oMMT nanocomposites and the decomposition temperature at $50 \%$ weight loss ( $T_{d 50}$ ) increased by $7.5{ }^{\circ} \mathrm{C}$ when the o-MMT content was $10 \mathrm{wt} \%$. The tensile strength value of the neat blend was obtained as 32.51 $\mathrm{MPa}$ and found to increase as $36.01 \mathrm{MPa}$ when the o-MMT content was $6 \mathrm{wt} \%$ in the system. The water absorption test results demonstrated that the water-resistance of the samples enhanced as the o-MMT content increased. Moreover, PVC/ASA blends exhibited a significant increase in the contact angle by the presence of hydrophobic o-MMT. The weathering test results demonstrated that the PVC/ASA/O-MMT nanocomposite films could be used for outdoor applications without apparently losing their properties.
\end{abstract}

Keywords: PVC/ASA blend, o-MMT, nanocomposite, weathering test.

Submitted: October 20, 2019. Accepted: June 22, 2020.

Cite this: KÖKÇAN Y, TAMER Y. Effect of o-MMT Content on Properties of Poly (vinyl chloride)/Poly (acrylonitrile styrene acrylate) Blends. JOTCSA. 2020;7(3):635-48.

DOI: https://doi.org/10.18596/jotcsa.635095.

*Corresponding author. E-mail: yasemin.tamer@yalova.edu.tr.

\section{INTRODUCTION}

Poly(vinyl chloride), PVC) is currently the third most commercially produced plastic after polyethylene and polypropylene, which is used extensively for window profiles, transportation, construction, and packaging due to its versatility, excellent mechanical strength, high chemical resistance and low cost (13). PVC is produced in two types, first rigid PVC and second soft or plasticized PVC (4). Flexible, plasticized PVC is softer and capable of bending due to the addition of plasticizers and is commonly used in construction. Rigid PVC is one of the most economically and technically important thermoplastic polymers; however, the major weakness of PVC such as brittleness and poor thermal stability limits its application $(5,6)$.
Therefore, to give more flexibility, to enhance impact strength and to expand the application range of PVC, impact modifiers can be used as additives, or processes such as chemical modification, compounding or blending with conventional polymers can be applied. Improving desired material properties or giving new properties to PVC with these methods, have become of great academic and industrial interest and various studies have been reported in recent years $(7,8)$.

Among these methods, polymer blending is a versatile, handy, and low-cost method to obtain a new material with desired features by combining two or more different polymers. The low impact strength of rigid PVC can be enhanced by adding a low glass transition temperature $\left(T_{g}\right)$ impact 
modifiers (9). It has been shown that the impact strength of rigid PVC enhances by blending with traditional rubber/elastomers such as ethylene-vinyl acetate (EVA), chlorinated polyethylene (CPE) and acrylonitrile-butadiene rubber (NBR). But, they form semi-compatible polymers and therefore become insufficient to meet the desired material properties (10-12). Recently, styrene-based copolymers with core-shell structure such as acrylonitrile butadiene styrene (ABS), methacrylate butadiene styrene (MBS) and methacrylate acrylonitrile butadiene styrene (MABS) have been widely studied to improve the impact strength and lower thermal dimensional stability of the PVC matrix by increasing the interfacial interaction between the PVC matrix and the rubber particles (13-16).

However, for outdoor applications, blending PVC using ABS, MBS or MABS can cause lower weathering durability of the PVC and the blends tend to yellow over time due to the unsaturated polybutadiene rubber moiety that is unstable to heat and UV light $(17,18)$. To overcome this problem, a new thermal stable polymer, poly (acrylonitrile styrene acrylate) (ASA) having saturated main polymer chains, might be used as an impact modifier for PVC. ASA has a core-shell structure, comprising a polyacrylate rubber core which is surrounded by styrene-acrylonitrile (SAN) copolymer shell (19). PVC easily interacts with the rigid shell phase due to their respective polarities rather than the rubber core phase. The interfacial adhesion between SAN and PVC is a significant factor to ensure optimum compatibility between the softcore and PVC matrix and is influenced by the acrylonitrile content in the SAN. The polyacrylate core is usually responsible for the toughening of the rigid PVC $(14,20,21)$. When exposed to UV, heat, or moisture, ASA copolymer exhibits a low level of discoloration and anti-aging performance due to the acrylic ester moiety in the matrix compared to ABS terpolymer. Furthermore, the thermal stability of the rubber core of ASA is much higher than the polybutadiene in ABS, and this is very important for the blend systems that need high processing temperatures $(2,22)$.

Polymer nanocomposites have remarkable potential and industrial interest in the development of advanced materials for countless applications. Nanoparticles in the form of fiber, tube, sphere or platelet are used to enhance mechanical, electrical, and thermal properties of the polymers even at low concentrations $(23,24)$. Montmorillonite (MMT) clay is one of the common nanofillers used for the development of new polymeric nanocomposites due to its high surface area, high aspect ratio, wide availability and relatively low cost (25). Pristine MMT clay has a hydrophilic structure and the silicate layers are held tightly together by electrostatic forces. It can form a homogeneous mixture with hydrophilic polymers such as poly(vinyl alcohol) and poly(ethylene oxide); however, it forms poor nanoclay dispersion in hydrophobic organic matrices. For instance, the dispersion of multilayer MMT clay into the PVC matrix is inhibited by incompatibility between hydrophilic layered silicate and the low polarity of PVC (26). To facilitate the compatibility, and create a homogenous mixture, surface modification is generally required. This can be easily achieved by replacing inorganic cations with organic cations that make hydrophilic MMT more organophilic. Therefore, MMT clay is often treated with alkylammonium salts to alter the surface polarity of the clay and to improve the wettability of the polymer by widening the interlayer spacing of MMT (27). So the polymer chains can easily reach the gap between the organophilic MMT (o-MMT) layers.

Several studies have reported regarding the PVC/ASA blends and its nanocomposites. Wang et al. (28) studied the influence of multi-walled carbon nanotubes (MWCNTs) on plasticizing behavior, mechanical properties and thermal stability of PVC/ASA blends, and the impact strength was found to be $83.7 \%$ higher than pure PVC/ASA blend for MWCNT content of 0.054 wt\%. Rimdusit et al. (2) discussed the effect of coconut fiber contents on mechanical, thermal, and physical properties of PVC/ASA blends, and they found a tensile strength value of $45 \mathrm{MPa}$ with the addition of $50 \mathrm{wt} \%$ coconut fibers to the blend structure. In another study conducted by Rimdusit et al. (8), the effect of ASA content on water absorption, mechanical properties, and outdoor weathering durability of PVC/ASA blends was investigated. By increasing ASA content, a drastic increase in the impact strength of the PVC/ASA blends was observed and the highest value was obtained as $77.6 \mathrm{~kJ} / \mathrm{m}^{2}$ when ASA content is $50 \mathrm{wt} \%$.

Although there have been various studies revealing the properties of PVC/ASA blends, authors believe that this is the first work that shows the effects of organophilic montmorillonite content on the mechanical and thermal properties, and the weatherability of PVC/ASA blends. In this research, PVC/ASA blends at a fixed ratio of $70 / 30 \mathrm{wt} \%$, and its o-MMT nanocomposites were prepared through solution casting. The effects of the o-MMT content on physical, mechanical, thermal, and weather resistance properties of the obtained composites were determined.

\section{MATERIALS AND METHODS}

\section{Materials}

PVC powder (Suspension PVC K-70, density 0.44$0.53 \mathrm{~g} / \mathrm{cm}^{3}$ ) and ASA granules were kindly supplied by Bayegan Plastics Co. (Istanbul, Turkey) and Chemieuro (Istanbul, Turkey), respectively. 
Organophilic montmorillonite (Nanomer I.31PS) was obtained from Sigma-Aldrich, which is clay modified by $15-35$ wt $\%$ octadecylamine and 0.5-5 wt\% aminopropyltriethoxysilane. The solvent tetrahydrofuran (THF, $99.5 \%$ ) was purchased from Sigma-Aldrich. Before solving, PVC powder and ASA granules, and o-MMT nanoparticles were dried at 80 ${ }^{\circ} \mathrm{C}$ for $5 \mathrm{~h}$.

\section{Preparation of PVC/ASA/o-MMT Nanocomposites}

The PVC/ASA/o-MMT nanocomposite films with different of o-MMT ratios were prepared by solution blending of PVC and ASA. In a typical preparation procedure, PVC and ASA were individually dissolved in THF; and afterward, the solutions were brought together and stirred overnight at room temperature. o-MMT dispersions were prepared in THF by using an ultrasonic homogenizer (Bandelin HD2200) for $60 \mathrm{~min}$ and then magnetically stirred for $24 \mathrm{~h}$ until the solutions became homogeneous. Subsequently, the prepared o-MMT dispersions were added to the solutions of PVC/ASA, and the resulting dispersions were placed in an ultrasonic bath for $3 \mathrm{~h}$ to obtain a homogeneous mixture. The dispersions were poured in Petri dishes and were allowed to dry at room temperature for $72 \mathrm{~h}$, under vacuum for $24 \mathrm{~h}$, and finally at $70{ }^{\circ} \mathrm{C}$ for $6 \mathrm{~h}$. The obtained films were hotpressed at $170{ }^{\circ} \mathrm{C}$ for $2 \mathrm{~min}$ followed by cooling to room temperature for further tests. The o-MMT content of the PVC/ASA/o-MMT nanocomposites was given in Table 1.

\section{Characterization Methods}

The Fourier transform infrared spectrophotometer (FTIR, Perkin Elmer, Spectrum 100) was used in ATR (Attenuated Total Reflection) mode in the wavenumber range $650-4000 \mathrm{~cm}^{-1}$ to confirm the structure of the PVC/ASA/o-MMT nanocomposites.

The thermal stability of PVC/ASA blends with various o-MMT amounts was determined using a thermogravimetric analyzer (Seiko, TG/DTA 6300) in the temperature ranges between room temperature to $800{ }^{\circ} \mathrm{C}$ at a heating rate of $10^{\circ} \mathrm{C} \mathrm{min}-1$ under $\mathrm{N}_{2}$ atmosphere.

The surface morphology of the PVC/ASA/o-MMT nanocomposite films was assessed by using a scanning electron microscope (SEM, FEI Inc., Inspect S50) operating at the $15 \mathrm{kV}$ accelerating voltage in secondary electron imaging mode. The tensile fracture surface of the samples was coated with thin gold film before measurement.

Tensile properties of the neat PVC, neat ASA, PVC/ASA blend, and its nanocomposites were determined using a universal tensile test machine (Zwick/Roell) equipped with a $1 \mathrm{kN}$ load cell at 25 ${ }^{\circ} \mathrm{C}$ according to ASTM D882. The crosshead speed was $10.0 \mathrm{~mm} \mathrm{~min}^{-1}$. The test specimens with a rectangular shape $(1 \mathrm{~cm} \times 10 \mathrm{~cm})$ and $0.8 \mathrm{~mm}$ thickness were cut from pressed thin plastic sheets. Mean values were obtained from five measurements of each sample.

Water absorption measurement was conducted according to gravimetric methods. Before testing, initial weights $\left(\mathrm{m}_{\mathrm{i}}\right)$ of specimens were recorded after drying them in an oven at $80{ }^{\circ} \mathrm{C}$ for $24 \mathrm{~h}$ and cooled down to room temperature. These dry specimens were immediately soaked in distilled water and waited for the samples to reach constant weight by weighing periodically. These final weights $\left(m_{f}\right)$ of the samples were recorded and the water absorption percentage of the samples (WA) was calculated by using the following equation:

$$
W A(\%)=\left(\frac{m_{f}-m_{i}}{m_{i}}\right) \times 100
$$

Contact angle measurement was carried out using a contact angle meter (KSV Instruments Cam 200) by measuring the contact angle of $5 \mu \mathrm{L}$ volume of distilled water drop on the film surface. The mean contact angle value of each sample was calculated from 5 measurements.

The density of samples was measured by water displacement method with a density kit attached to a balance (AND brand AHR-AZ model) using ethanol as a reference liquid. The mean of 5 measurements was given as the density value of each sample.

The heating-cooling cycling tests were performed. In a typical test, the sample was immersed in distilled water for $24 \mathrm{~h}$ at room temperature followed by freezing in a freezer at $-40{ }^{\circ} \mathrm{C}$ for $24 \mathrm{~h}$. Then, the sample was removed from the freezer and allowed to thaw at room temperature, and afterward, it was placed in an oven at $40{ }^{\circ} \mathrm{C}$ for another $24 \mathrm{~h}$. The same procedure was repeated four times; and at the end of the test, the SEM image of the sample was taken, and the tensile test was performed to assess the property changes.

\section{RESULTS AND DISCUSSION}

The hydrophilic nature of MMT prevents the formation of homogeneous nanocomposites. Therefore, the silicate layers of MMT must be organically modified with a proper modification agent to enhance dispersion in polymer matrix before polymer/MMT composites are prepared. In this work, a commercial o-MMT modified with 15-35 $w t \%$ octadecylamine (ODA) and 0.5-5 wt\% aminopropyltriethoxysilane (APTES) was used to prepare the PVC/ASA/o-MMT nanocomposites with a fixed PVC/ASA weight ratio of 70/30. Octadecylamine is a primary alkyl amine mainly used as a hydrophobic surface modifier for different 
carbon nanomaterials; while APTES, an amino silane, is generally used in the chemical modification of surfaces; and acts as an adhesion promoter between the polymer and the filler $(29,30)$. Since the carbon chain length of organically modified MMT is decisive on the size of the interlayer space, the chemical structure of the surface modifier group is of primary importance (31). Also, there have been several research papers addressing the usage of ODA modified clay in the preparation of PVC nanocomposites $(26,32,33)$.

\section{FTIR Analysis}

To identify the possible intermolecular interaction between PVC, ASA, and o-MMT nanoparticles, FTIR spectra of neat PVC, neat ASA, PVC/ASA blends, and its o-MMT nanocomposites was depicted in Figure

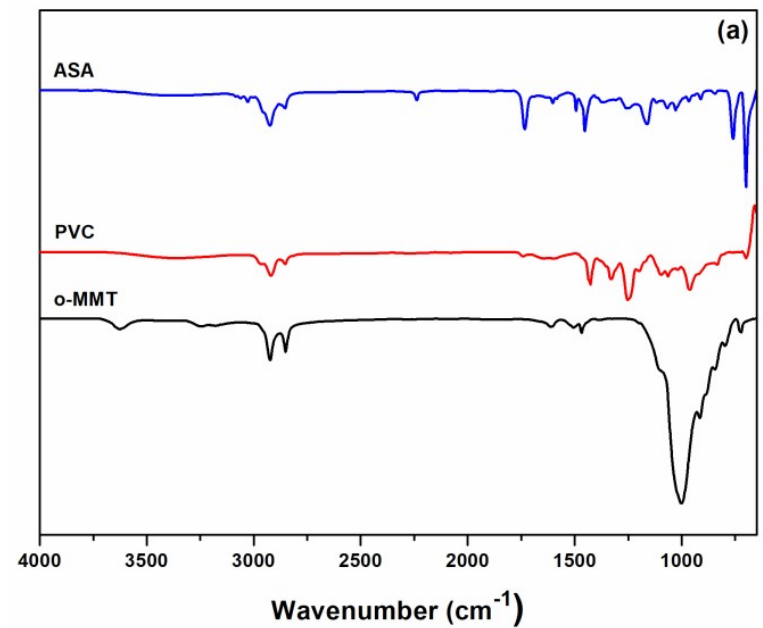

$1 a, b$. For neat PVC, the characteristic peak belong to $\mathrm{C}-\mathrm{Cl}$ stretching vibration was seen at $694 \mathrm{~cm}^{-1}$, and the peak at $1428 \mathrm{~cm}^{-1}$ attributed to the $\mathrm{C}-\mathrm{H}$ deformation vibration of $\mathrm{CH}_{2}$ groups. The peaks at 2916 and $2854 \mathrm{~cm}^{-1}$ matched with the stretching vibrations of $\mathrm{C}-\mathrm{H}$ bonds (34). FTIR spectrum of ASA exhibited a characteristic broad peak at $1733 \mathrm{~cm}^{-1}$ assigned to the $\mathrm{C}=\mathrm{O}$ stretching vibration of the carboxyl group in PBA and a tiny peak at $2236 \mathrm{~cm}^{-1}$ belonging to $\mathrm{C} \equiv \mathrm{N}$ stretching vibration of the nitrile group in SAN. The peaks at 1452, 1495, $1604 \mathrm{~cm}^{-1}$, and $701-762 \mathrm{~cm}^{-1}$ were attributed to the stretching and bending vibrations of the benzene ring $(17,35)$. Moreover, the stretching vibrations of $\mathrm{C}-\mathrm{H}$ groups in benzene ring and polymer backbone were observed at $3027 \mathrm{~cm}^{-1}$ and $2928 \mathrm{~cm}^{-1}$, respectively.

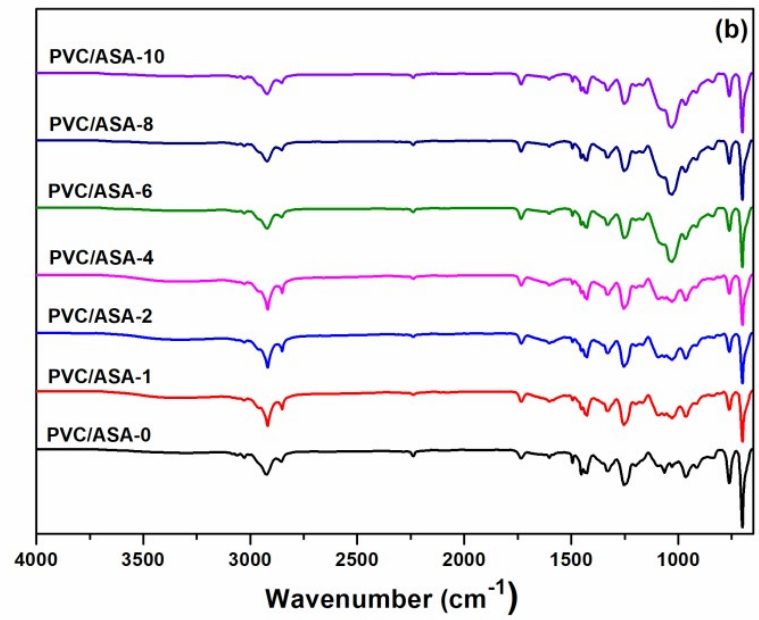

Figure 1. FTIR spectra of (a) PVC, ASA, and o-MMT, (b) PVC/ASA blend, and PVC/ASA/o-MMT nanocomposites.

FTIR spectrum of o-MMT nanoparticles exhibited a characteristic complex band at the position of about $1002 \mathrm{~cm}^{-1}$ attributed to the stretching vibrations of $\mathrm{Si}-\mathrm{O}$ groups (Figure $1 \mathrm{a}$ ). The peak corresponding to stretching vibrations of structural $\mathrm{OH}$ groups of the montmorillonite appeared at $3626 \mathrm{~cm}^{-1}$. The octadecylamine intercalated into the gallery of the MMT was verified with the bands at around 2923, 2851, and $3243 \mathrm{~cm}^{-1}$, for $\mathrm{C}-\mathrm{H}$ asymmetric and symmetric stretching of $\mathrm{CH}_{2}$ or $\mathrm{CH}_{3}$, and $\mathrm{N}-\mathrm{H}$ stretching of alkylammonium, respectively (36). In the FTIR spectra of PVC/ASA/o-MMT nanocomposite films, the distinctive peaks of both PVC and ASA, and the nanofiller were observed, proving the intermolecular interactions between them (Figure 1b). Moreover, the increment of o-MMT content in the nanocomposite enhanced the intensities of the characteristic 0-MMT peaks (for PVC/ASA-6, PVC/ASA-8, and PVC/ASA-10).

\section{Thermal Analysis}

Thermogravimetric analysis (TGA) is an analytical technique used to characterize the decomposition and thermal stability of materials and to determine the fraction of moisture and volatile compounds present in the structure by monitoring the mass change (37). The thermal decomposition of neat PVC, neat ASA, PVC/ASA blend, and its o-MMT composites investigated thermogravimetrically. The thermal weight loss curves of samples were shown in Figure $2 a, b$. On the TGA thermogram of neat PVC, the observed first step degradation from room temperature to about $160{ }^{\circ} \mathrm{C}$ was related to the removal of trapped THF and volatile compounds. As seen from the curve, two main weight loss regions occurred; the first weight loss region up to $350{ }^{\circ} \mathrm{C}$ corresponding to dehydrochlorination of polymer, and the second main weight loss in the temperature range between $410-530{ }^{\circ} \mathrm{C}$ due to the formation of volatile aromatic compounds and pyrolysis to low hydrocarbons $(38,39)$. It is clear from Figure $2 a$ that ASA had the highest initial decomposition temperature due to the presence of the SAN shell of ASA. The degradation profile of PVC/ASA between 260 and $400^{\circ} \mathrm{C}$ exhibited both the dehydrochloration of PVC and the degradation of ASA. 

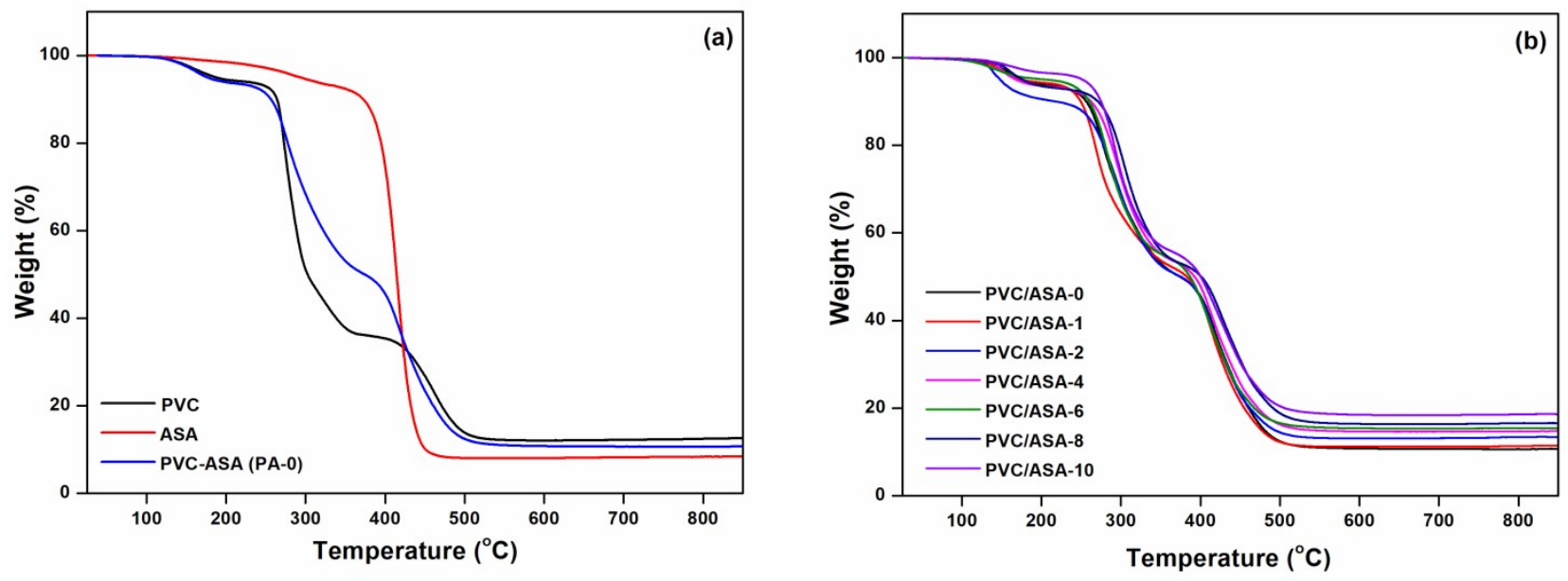

Figure 2. TGA thermograms of (a) neat PVC, neat ASA, and PVC/ASA blend, (b) PVC/ASA/o-MMT nanocomposites.

Figure 2b displayed the TGA thermograms of PVC/ASA/o-MMT nanocomposite films which were shifted to higher temperatures with the addition of o-MMT nanoparticles and their increased amounts in the PVC/ASA blend matrix. This result indicated the strong interaction between the components of the blend, thus led to restricted mobility of the polymer molecules which took part in the degradation process. Therefore, increased o-MMT amounts contributed to the increase in thermal stability (40).
The thermal stability of a material can be characterized as the temperature at which $50 \%$ mass is retained or lost $\left(T_{d 50}\right)(41)$. The $T_{d 50}$ and residue values of nanocomposites were given in Table 1. The $\mathrm{T}_{\mathrm{d} 50}$ of PVC/ASA/o-MMT nanocomposites increased by about $26{ }^{\circ} \mathrm{C}$ as a function of o-MMT content. Moreover, the residual mass amounts were found to be increased with increasing o-MMT amounts, as expected.

Table 1. Thermal analysis and tensile properties of neat PVC, neat ASA, PVC/ASA blend and its nanocomposites at various o-MMT contents.

\begin{tabular}{|c|c|c|c|c|c|}
\hline Samples & $\begin{array}{c}\text { o-MMT } \\
\text { content } \\
\text { (wt } \%)\end{array}$ & $\begin{array}{l}T_{d 50^{a}} \\
\left({ }^{\circ} \mathrm{C}\right)\end{array}$ & $\begin{array}{c}\text { Char yield } \\
\text { (wt\%) }\end{array}$ & $\begin{array}{l}\text { Tensile } \\
\text { Strength } \\
\text { (MPa) }\end{array}$ & $\begin{array}{c}\text { Tensile } \\
\text { Modulus } \\
\text { (GPa) }\end{array}$ \\
\hline PVC & 0 & 302.30 & 12.76 & $37.63 \pm 0.97$ & $1.86 \pm 0.18$ \\
\hline ASA & 0 & 414.45 & 8.48 & $27.88 \pm 1.42$ & $1.27 \pm 0.92$ \\
\hline PVC/ASA-0 & 0 & 374.09 & 10.00 & $32.51 \pm 2.24$ & $1.48 \pm 0.73$ \\
\hline PVC/ASA-1 & 1 & 375.10 & 11.50 & $32.55 \pm 1.72$ & $1.48 \pm 0.55$ \\
\hline PVC/ASA-2 & 2 & 382.73 & 13.50 & $34.79 \pm 2.43$ & $1.46 \pm 0.82$ \\
\hline PVC/ASA 4 & 4 & 386.80 & 14.90 & $35.60 \pm 0.97$ & $1.70 \pm 0.47$ \\
\hline PVC/ASA-6 & 6 & 392.50 & 15.50 & $36.01 \pm 1.75$ & $1.76 \pm 0.19$ \\
\hline PVC/ASA-8 & 8 & 400.10 & 16.80 & $31.42 \pm 1.34$ & $1.45 \pm 0.81$ \\
\hline PVC/ASA-10 & 10 & 402.10 & 18.70 & $27.82 \pm 1.18$ & $0.54 \pm 1.12$ \\
\hline
\end{tabular}

a Temperature at which $50 \%$ weight loss was verified by TGA.

b The weight percentage of undecomposed material after TGA analysis at $800{ }^{\circ} \mathrm{C}$.

\section{Tensile Properties}

The tensile properties of neat PVC, neat ASA, and PVC/ASA blends with different o-MMT content were given in Figure 3 and Table 1. The tensile strength and tensile modulus of neat PVC were $37.630 \mathrm{MPa}$ and $1.862 \mathrm{GPa}$ whereas those of ASA were 27.880 $\mathrm{MPa}$ and $1.269 \mathrm{GPa}$, respectively. PVC/ASA blend displayed tensile strength and tensile modulus values as $32.510 \mathrm{MPa}$ and $1.478 \mathrm{GPa}$, respectively; that is between neat PVC and neat ASA, as also being predicted by a rule of mixture. Previous studies in the literature such as PVC/ABS blends $(42,43)$, PC/ASA/SAN blends (44), and the PC/ABS blend (45) have also reported similar behavior. 


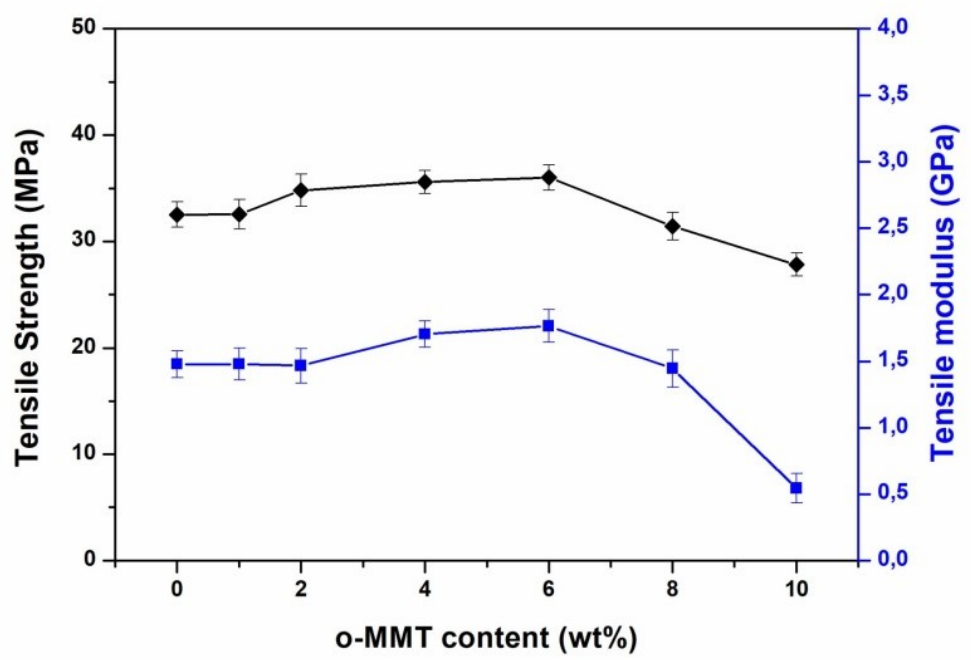

Figure 3. Tensile strength and tensile modulus of PVC/ASA/o-MMT nanocomposites. The data are represented as mean \pm standard deviation $(n=5)$.

For PVC/ASA/o-MMT nanocomposites, the tensile strength initially remained unchanged, and then an increment was observed with further increasing oMMT content. Although low concentrations of filler materials seemed ineffective, they contributed to load distribution as the concentration of filler materials increased (46). For instance, the tensile strength of the nanocomposites increased from 32.510 to $36.010 \mathrm{MPa}$ when the o-MMT amount increased from 2 to 6 wt\%. As can be seen from Figure 4, the tensile properties of PVC/ASA blends were negatively influenced by the high amount of oMMT (10 wt\%) used. This could be attributed to the poor dispersity of o-MMT and thus the formation of agglomerates. Homogeneous dispersion of nanofillers in the matrix is crucial to obtain nanocomposites with good mechanical properties (47).

In the case of increasing o-MMT amounts, tensile modulus showed similar behavior with tensile strength. As the o-MMT content increased up to a certain amount, the tensile modulus of PVC/ASA nanocomposites was found to increase, suggesting that o-MMT contributed to an improved stiffness of the nanocomposite (Figure 3). For example, by the increase in the o-MMT amount from 2 to $6 \mathrm{wt} \%$, the tensile modulus value increased from 1.478 to $1.764 \mathrm{GPa}$.

\section{SEM Analysis}

SEM micrographs of the tensile fracture surface of the samples were illustrated in Figure 4. Neat PVC exhibited typical rigid and brittle fracture morphology with a relatively smooth surface (17, 48). The fracture surface of the PVC/ASA blend (Figure 4) appeared rougher than pure PVC and exhibited microlayer structure due to the core-shell morphology of ASA with internal PBA core layer and outer SAN shell layer $(28,49)$. The structure gained some ductile characteristics with the incorporation of ASA and a corrugated and irregular fracture surface was observed.

As seen in Figure 4, the fracture surface of PVC/ASA/o-MMT nanocomposites was also rough as the neat blend, and there was no obvious change in SEM micrographs with the increase in the o-MMT content. SEM images of nanocomposites clearly showed that the good dispersion of o-MMT was achieved without the formation of any particle clusters, and most of the o-MMT was embedded in the PVC/ASA matrix. For the nanocomposites containing 1-6 wt\% of o-MMT, observation of no gaps, cavity, or agglomerates in the fracture surface indicated the good interfacial adhesion between filler and matrix. This finding was also consistent with the improved tensile properties of the PVC/ASA/o-MMT nanocomposites. Increasing o-MMT content from 6 wt $\%$ to $8-10$ wt\% resulted in the formation of a rough surface with some holes throughout the fractured sample surface (Figure 4). Although not detectable from SEM images, it was believed that oMMT aggregates were formed in the case of PVC/ASA-8 and PVC/ASA-10 nanocomposites. As can be seen in the higher magnification SEM image of PVC/ASA-10 (Figure 4), the regions marked by red circles were thought to be related to the agglomeration of o-MMT nanoparticles in the polymer matrix. Besides, the weak mechanical properties obtained in this high o-MMT content could be attributed to the formation of these agglomerates. 




Figure 4. SEM micrographs of PVC and PVC/ASA/o-MMT nanocomposites

\section{Water Absorption, Contact Angle and Density} Analysis

The capability of plastics to absorb moisture is a significant durability parameter to understand the performance of the materials. The moisture/water absorption can result in defects in the polymeric material such as swelling or dissolution of polymeric material, extraction of water-soluble components, or changes in mechanical (tensile strength, impact strength, elasticity) and electrical performance (2, 50).

The results of water absorption percentages as a function of time were shown in Figure 5. After soaking for around 24 hours, the water absorption percentage of pure PVC was 0.08 wt\% while
PVC/ASA blend showed a higher value of 0.29 wt\%. The reason was the high water absorption value of pure ASA of about 0.42 wt\% due to its highly polar acrylonitrile moiety. As depicted in Figure 5, no significant changes were observed in the water absorption percentages of the nanocomposites with small amounts of o-MMT incorporation. (PVC/ASA-1 and PVC/ASA-2) Then, the water uptakes of nanocomposites were found to decrease from 0.29 wt $\%$ to 0.10 wt\% as the amount of $0-M M T$ reaches 4 wt\% to 8 wt\%. Furthermore, the absorption increased to about 0.20 wt\% with the addition of 10 wt\% o-MMT to the structure due to the formation of agglomerates. This phenomenon was also proved by contact angle measurement. 


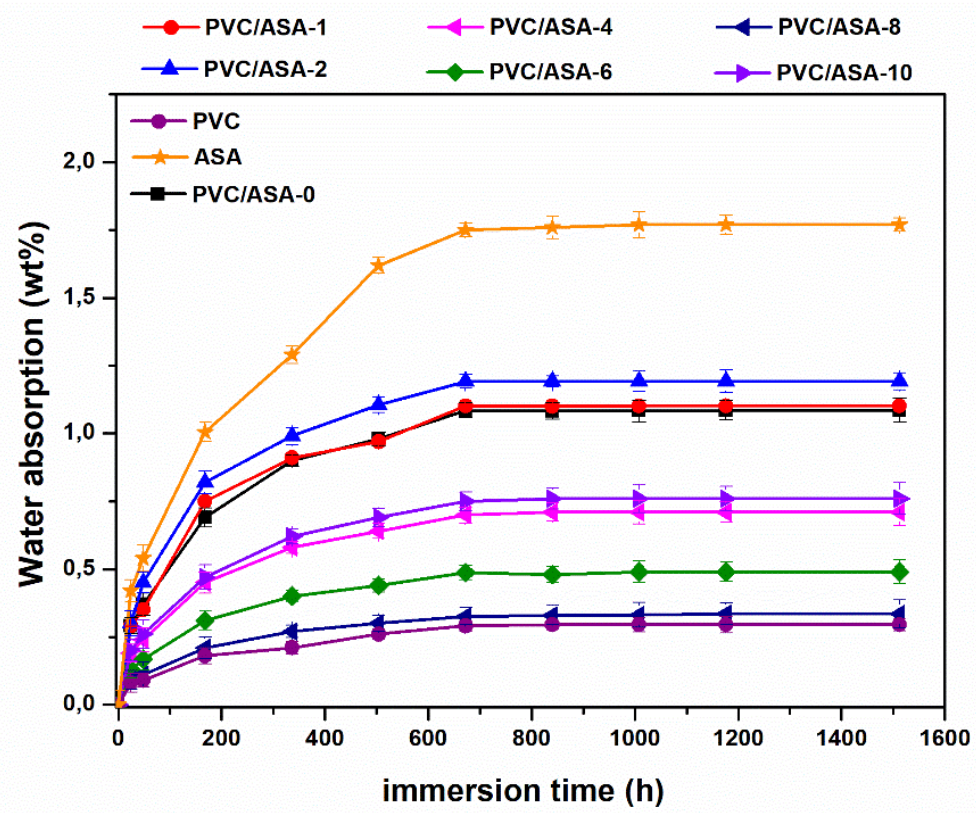

Figure 5. Water absorption of PVC, ASA, PVC/ASA, and PVC/ASA/o-MMT nanocomposites. The data are represented as mean \pm standard deviation $(n=3)$.

The measured water contact angle values of the nanocomposites as a function of o-MMT content were given in Figure 6 . The contact angle value was found to be $97^{\circ}$ and $87^{\circ}$ for the pure PVC and ASA, respectively. The PVC/ASA blend prepared by adding 30 wt\% ASA showed a contact angle of about $94^{\circ}$ between these values, similar to water absorption results. The contact angle measurement gives information about the affinity of the surface for water. Higher contact angle values show the hydrophobic surfaces that are more resistant against water while lower values represent hydrophilic surfaces that have an affinity for water. The contact angle value is directly related to the chemical composition of the surface (51).

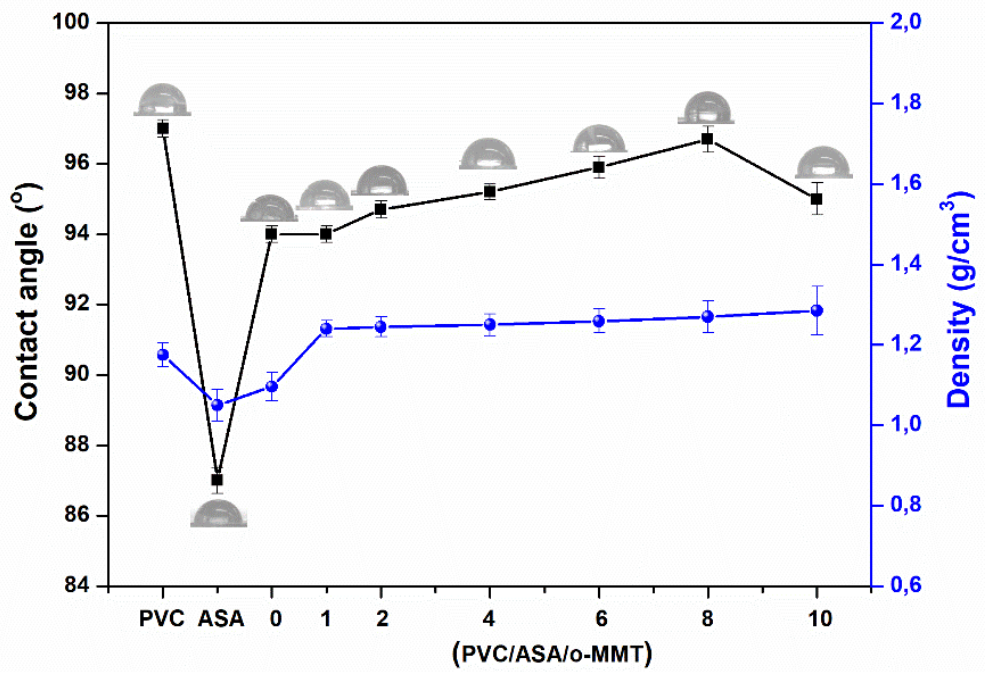

Figure 6. Contact angle and density values of PVC, ASA, PVC/ASA, and PVC/ASA/o-MMT nanocomposites. The data are represented as mean \pm standard deviation $(n=5)$.

The incorporation of hydrophobic o-MMT into the PVC/ASA blend matrix caused no significant differences in the physicochemical surface characteristics of nanocomposites for PVC/ASA-1 and PVC/ASA-2, while its increasing amounts considerably increased the surface contact angle of PVC/ASA nanocomposites (Figure 6). As expected, the increment in o-MMT content enhanced the hydrophobic character of the nanocomposite surface. However, a sudden decrease in contact angle value of about $95^{\circ}$ was observed for the blends with high o-MMT content (PVC/ASA-10) due to agglomeration of o-MMT particles. As the nanoparticles aggregate, the nanoparticle and 
polymer interface became narrower and nonhomogeneous surfaces were formed, and this led to a decrease in the hydrophobicity effect of the oMMT. The contact angle measurements were consistent with SEM analysis and tensile test results.

Density measurement of a nanocomposite is an important physical parameter and can be effectively used to ensure product quality and homogeneity and to monitor manufacturing processes. For instance, the presence of voids or defects has several negative effects on the material properties particularly mechanical properties of the composite (8). The experimental densities determined by weighing the sample in air and then in ethanol of known density were given in Figure 6 . It can be seen that PVC/ASA structure gave an experimental density value of about $1.096 \mathrm{~g} \mathrm{~cm}^{-3}$ between the density of the neat PVC of $1.175 \mathrm{~g} \mathrm{~cm}^{-3}$ and the density of the neat ASA of $1.050 \mathrm{~g} \mathrm{~cm}^{-3}$. The theoretical density of PVC/ASA (70/30 wt\%) blend was also estimated according to the rule of a mixture by using the measured density values of PVC and ASA, and it is found to be $1.137 \mathrm{~g} \mathrm{~cm}^{-3}$. The obtained theoretical density value is in good agreement with the measured experimental density value, suggesting the negligible amount of void in the blend sample. Thus, the homogeneity of the obtained structure proved again. The density of PVC/ASA/o-MMT composites as increasing o-MMT content to $1,2,4,6,8$, and 10 wt\% was measured to be $1.240,1.245,1.250,1.259,1.270$ and $1.285 \mathrm{~g}$ $\mathrm{cm}^{-3}$, respectively (Figure 6). Based on the measured density values, o-MMT reinforced composites showed higher density values compared to neat PVC/ASA blend, and the obtained density values tended to increase slightly with increasing oMMT amounts.

\section{Weathering Test}

Plastic materials are exposed to the effects of climate changes (cool, heat, rain, UV, etc.) during their life cycle. Fluctuations in ambient temperature directly affect the mobility of the long polymer chains, and thus the final properties of plastics such as color, brilliance, hardness, flexural, or impact strength. Accordingly, it is important to know how polymers perform when subjected to external heat changes. High temperatures can cause the mobility of the polymer chains and crystalline structure changes occur, or temperatures lower than $\mathrm{Tg}$ of material immobilize polymer chains and the material becomes fragile (52).

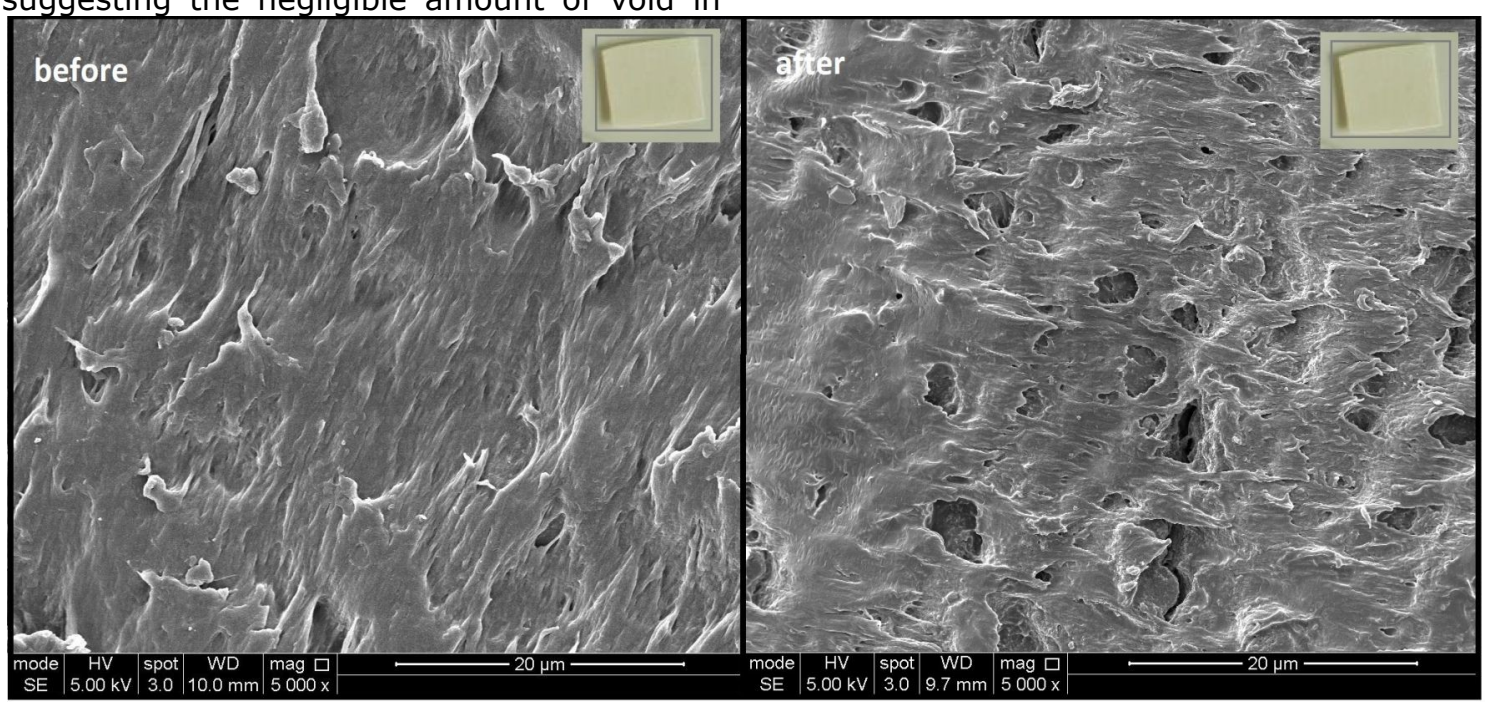

Figure 7. SEM micrographs of PVC/ASA-6 before and after four heating-cooling cycles.

A modified freeze-thaw cycling test was applied to determine the effect of ambient temperature changes on the durability of PVC/ASA-6 nanocomposite having the best material properties. After four heating-cooling cycles, comparisons were performed on the mechanical properties and morphology of the exposed and unexposed samples. SEM images of the two samples were taken of the fracture surface after tensile testing to assess if temperature changes affected the interfacial adhesion between o-MMT and PVC-ASA matrix. As seen from the embedded images in Figure 8 , no changes in the visual appearance of PVC/ASA-6 samples were detected such as crack formation, color change, or surface roughness. However, there were some gaps or crevices in the SEM image (Figure 7) of the exposed PVC/ASA-6 sample; these were probably due to the decreased interfacial adhesion between PVC and ASA polymers.

The tensile strength and tensile modulus of unexposed PVC/ASA-6 samples were $36.010 \mathrm{MPa}$ and $1.764 \mathrm{GPa}$; whereas the values decreased to 34.920 MPa and $1.645 \mathrm{GPa}$, respectively, after exposure to four heating-cooling cycles. This decline could be attributed to the degradation of interfacial 
adhesion between PVC and ASA and hence lowstress transfer at the interface as a result of exposure to moisture. Besides, the sample was immersed in water to ensure enough moisture before freeze-thaw cycles and then, the volume expansion of water occurred while the sample freezes down. Then, removal of the water during the thawing process might result in voids which could lead to mechanical failure (Figure 7) (53).

\section{CONCLUSIONS}

In this research, the fabrication of PVC/ASA/o-MMT nanocomposites with a fixed PVC/ASA weight ratio of 70/30 was demonstrated. The resultant nanocomposites were characterized using FTIR, TGA, SEM, and tensile test units. The effects of oMMT content on the mechanical properties, thermal properties, and water absorption of the PVC/ASA blends examined in detail. With the addition of $6 \mathrm{wt}$ $\%$ o-MMT, the highest tensile strength value, i.e. 36.01 MPa was obtained for PVC/ASA-6 nanocomposite. Also, the thermal stability of PVC/ASA/o-MMT nanocomposites improved with oMMT incorporation to the blend; the temperature referring $50 \%$ mass loss, $T_{d 50}$ increases as a function of O-MMT content. Furthermore, water absorption of these nanocomposites slightly decreased with the o-MMT content due to increased hydrophobicity of the structure. Weathering test results demonstrated that the loss in tensile properties due to the exposure to heating-cooling cycles was not critical, although some voids were observed on the PVC/ASA nanocomposite fracture surface.

\section{ACKNOWLEDGMENT}

The authors thank Bayegan Plastics Co. and Chemieuro companies for the kind donation of supplies. This article was presented in the 31st National Chemistry Congress and submitted to JOTCSA as a full manuscript.

\section{REFERENCES}

1. Sree KB, Kumar YM, Gopal NO, Ramu C. Preparation and characterization of pure and copper-doped PVC films. J Polym Eng. 2017;37(1):83-92. DOI:10.1515/polyeng-20150446.

2. Sarawut R, Siriporn D, Patima W, Duangporn S, Sunan T. Characterization of coconut fiber-filled polyvinyl chloride/acrylonitrile styrene acrylate blends. J Reinf Plast Comp. 2011;30(20):16911702 DOI: $10.1177 / 0731684411427484$.

3. Bijhanmanesh MJ, Etesami N, Darvishi R. Continuous dosing of fast initiator during vinyl chloride suspension polymerization: thermal stability of PVC resin. J Appl Polym Sci. 2017;134(1):4448087. DOI: $10.1002 /$ APP. 44480.

4. Zhang $X$, Zhang J. Effect of temperature on the impact behavior of PVC/ASA binary blends with various ASA terpolymer contents. J Polym Eng. 2019;39(5):407-414. DOI:10.1515/polyeng-20180349.

5. $\mathrm{Yu} \mathrm{J}$, Feng $\mathrm{P}$, Zhang $\mathrm{H}$. Effects of core-shell acrylate particles on impact properties of chlorinated polyethylene/polyvinyl chloride blends. Polym Eng Sci. 2010;50(2):295-301. DOI:10.1002/pen.21539.

6. Zhang Z, Wang S, Zhang J, Zhu W, Tian T. Remarkably improved toughness and thermal stability of poly (vinyl chloride) (PVC)/poly (amethylstyrene-acrylonitrile) (a-MSAN) blend with the assistance of two impact modifiers. Polym Test. 2016;51:1-5.

DOI:10.1016/j.polymertesting.2016.02.003.

7. Zhang Z, Chen S, Zhang J. Improvement in the heat resistance of poly(vinyl chloride) profile with styrenic polymers. J Vinyl Addit Techn. 2011;17(2):85-91. DOI:10.1002/vnl.20251.

8. Rimdusit $\mathrm{S}$, Wongmanit $\mathrm{P}$, Damrongsakkul $\mathrm{S}$, Saramas D, Jubsilp C, Dueramae I. Characterizations of poly(vinyl chloride)/acrylonitrile styrene acrylate blends for outdoor applications. Eng ]. 2013;18(1):105-118. DOI: $10.4186 /$ ej.2014.18.1.105

9. Mao Z, Zhang J. Largely improved the low temperature toughness of acrylonitrile-styreneacrylate (ASA) resin: Fabricated a core-shell structure of two elastomers through the differences of interfacial tensions. Appl Surf Sci. 2018;444,345354. DOI:10.1016/j.apsusc.2018.03.066.

10. You F, Chen G, Zou J, Yang Z, Guo S. The experimental results and simulation of temperature dependence of brittle-ductile transition in PVC/CPE blends and PVC/CPE/nano-CaCO3 composites. J. Appl. Polym. Sci. 2012,123(3), 1833-1842. DOI:10.1002/app.34662.

11. Chen M, Wang S, Zhou C, Liu Z, Zhang $H$. Toughening Poly (Vinyl Chloride) by PS/PB/PMMA Three-Layer Particles. Polym Plast Dent Eng. 2013;52(8):814-819.

DOI: $10.1080 / 03602559.2013 .763359$.

12. Markarian J. Impact modifiers: how to make your compound tougher. Plast Addit Compd $2004 ; 6(3): 46-49$. 391X(04)00203-X. DOI: $10.1016 / S 1464-$

13. Wang $\mathrm{HL}$, Tan $\mathrm{HS}, \mathrm{Li} \mathrm{YJ}, \mathrm{Yu} \mathrm{YZ}$. Phase morphology and dynamic mechanical behavior for 
MIS toughened polyvinyl chloride. J Appl Polym Sci. 2013;129(6):3466-3472. DOI:10.1002/app.39095.

14. Wu S, Chen M, Wu G, Zhou C. Variation of coreshell structural particles and their toughening behavior in poly (vinyl chloride) (PVC) matrix. J Polym Res (2015);22:82. DOI: $10.1007 /$ s10965015-0730-6.

15. Scott G, Tahan M. The photo-oxidation of PVC and impact modified PVC. Chemical changes. Eur Polym J. 1977;13(12):989-996. DOI:10.1016/00143057(77)90171-9.

16. Zhang LX, Zhou C, Sun SL, Ren L, Ma XL, Zhang MY, Zhang HX. Study of compatibility, morphology structure and mechanical properties of CPVC/ABS blends. J Appl Polym Sci. 2010;116(6):3448-3454. DOI:10.1002/app.31855.

17. Zhang $Y, X u Y$, Song $Y$, Zheng $Q$. Study of poly(vinyl chloride)/acrylonitrile-styrene-acrylate blends for compatibility, toughness, thermal stability and UV irradiation resistance. J Appl Polym Sci. 2013;130(3):2143-2151. DOI:10.1002/APP.39405.

18. Pickett JE, Gibson DA, Gardner MM. Effects of irradiation conditions on the weathering of engineering thermoplastics. Polym Degrad Stab. 2008;93(8):1597-1606.

DOI:10.1016/j.polymdegradstab.2008.02.009.

19. Du YG, Gao JG, Yang JB, Liu XQ. Dynamic rheological behavior and mechanical properties and of PVC/ASA blends. J Polym Res. 2012;19(11): 9993. DOI: $10.1007 /$ s10965-012-9993-3.

20. Gawade AR, Lodha AV, Joshi PS. PVC/ABS blends: Thermal and morphological studies. J Macr Sci. Part B: Physics. 2008;47(1):201-210. DOI: $10.1080 / 00222340701748701$.

21. Yin B, Hakkarainen M. Core-shell nanoparticleplasticizers for design of high-performance polymeric materials with improved stiffness and toughness. J. Mater. Chem. 2010;21(24):86708677. DOI:10.1039/C1JM10624D.

22. Szamborski G. Superior balance of weatherability and impact performance with acryliccapped vinyl siding. J Vinyl Addit Tech. 2007;13(1):26-30. DOI:10.1002/vnl.20094.

23. Crosby AJ, Lee JY. Polymer nanocomposites: The "nano" effect on mechanical properties. Polym. Rev. 2007; 47(2):217-229.

DOI: $10.1080 / 15583720701271278$.

24. Pagacz J, Pielichowski K. PVC/MMT nanocomposites. J Therm Anal Calorim
2013;111(2):1571-1575. 012-2484-2.

25. Guo F, Aryana S, Han Y, Jiao Y. A review of the synthesis and applications of polymer-nanoclay composites. Appl Sci. 2018;8(9):1696. DOI: $10.3390 / a p p 8091696$.

26. Ismail $\mathrm{H}$, Munusamy $\mathrm{Y}$. Polyvinyl Chloride/Organoclay Nanocomposites: Effects of Filler Loading and Maleic Anhydride. J Reinf Plastc Comp. 2007;26(16):1681-1694. DOI: $10.1177 / 0731684407081446$.

27. Mondragon M, Valdes SS, Sanchez-Espindola ME, Rivera-Lopez JE. Morphology, mechanical properties, and thermal stability of rigid PVC/Clay nanocomposites. Polym Eng Sci. 2011;51(4):641646. DOI:10.1002/pen.21867.

28. Wang C, Li N, Huo L, Gao J. Effect of carbon nanotube on the mechanical, plasticizing behavior and thermal stability of PVC/poly(acrylonitrilestyrene-acrylate) nanocomposites. Polym Bul. 2015;72(8):1849-1861. DOI:10.1007/s00289-015$1376-6$.

29. Li W, Tang XZ, Zhang HB, Jiang ZG, Yu ZZ, Du $X S$, Mai YW. Simultaneous surface functionalization and reduction of graphene oxide with octadecylamine for electrically conductive polystyrene composites. Carbon. 2011;49(14)47244730. DOI:10.1016/j.carbon.2011.06.077.

30. Pasternack RM, Amy SR, Chabal YJ. Attachment of 3-(aminopropyl) triethoxysilane on silicon oxide surfaces: Dependence on solution temperature. Langmuir. 2008;24(22):12963-12971. DOI: $10.1021 / 1 a 8024827$.

31. Liang ZM, Wan $C Y$, Zhang $Y$, Wei $P$, Yin $J$. PVC/Montmorillonite Nanocomposites Based on a Thermally Stable, Rigid-Rod Aromatic Amine Modifier. J Appl Polym Sci. 2004;92:567-575. DOI:10.1002/app. 20041.

32. Shimpi NG, Mishra S. Influence of surface modification of montomorillonite on properties of PVC nanocomposites. J Comp Mat. 2011;45(23):2447-2453. DOI: $10.1177 / 0021998311401095$.

33. Wan C, Qiao X, Zhang Y, Zhang Y. Effect of different clay treatment on morphology and mechanical properties of PVC-clay nanocomposites. Polym Test. 2003;22(4):453-461. DOI: $10.1016 / \mathrm{S} 0142-9418(02) 00126-5$

34. Ramesh S, Leen KH, Kumutha K, Arof AK. FTIR studies of PVC/PMMA blend based polymer electrolytes. Spectrochim Acta Part A Mol Biomol 
Spectrosc. 2007;66(4-5):1237-1242. DOI:10.1016/ j.saa.2006.06.012.

35. Orlov AS, Kiselev SA, Kiseleva EA, Budeeva AV, Mashukov VI. Determination of styrene-butadiene rubber composition by attenuated total internal reflection infrared spectroscopy. J Appl Spectrosc. 2013;80(1):47-53. DOI:10.1007/s10812-013-97192.

36. Chuayjuljit $S$, Thongraar $R$, Saravari $O$. Preparation and properties of PVC/EVA/Organomodified montmorillonite nanocomposites. J Reinf Plast Comp. 2008;27(4):431-442.

DOI: $10.1177 / 0731684407084124$.

37. Datta P, Guha C, Sarkhel G. Effect of $\mathrm{Zn}^{+2}$ poly(ethylene-co-methacrylic acid) ionomer on mechanical properties, thermal properties, morphology and process rheology of acrylonitrile styrene acrylate (ASA) terpolymer. Polym Plast Tech Eng. 2014;53(1):80-89. DOI: $10.1080 / 03602559.2013 .843692$.

38. Hasan $M$, Kumar $R$, Barakat MA, Lee $M$. Synthesis of PVC/CNT nanocomposite fibers using a simple deposition technique for the application of Alizarin Red S (ARS) removal. RSC Adv. 2015;5:14393-14399. DOI:10.1039/C4RA16043F.

39. Joseph J, Deshmukh K, Chidambaram K, Faisal M, Selvarajan E, Sadasivuni KK, Ahamed MB, Khadheer Pasha SK. Dielectric and electromagnetic interference shielding properties of germanium dioxide nanoparticle reinforced poly(vinyl chloride) and poly(methylmethacrylate) blend nanocomposites. J Mat Sci: Mat Elect. 2018;29(23):20172-20188. DOI: $10.1007 /$ s10854018-0150-6.

40. Sathyanarayana S, Olowojoba G, Weiss P, Caglar B, Pataki B, Mikonsaari I, Hübner C, Henning F. Compounding of MWCNTs with PS in a twin-screw extruder with varying process parameters: Morphology, interfacial behavior, thermal stability, rheology, and volume resistivity. Macromol. Mater. Eng.

DOI: $10.1002 / m a m e .201200018$.

41. Datta P, Guha C, Sarkhel G. Thermal, dynamic mechanical, and creep behavior of carbon nanotube reinforced ASA/Na-ionomer blend. Polym Adv Technol. $2015 ; 26(10): 1294-1301$. DOI: $10.1002 /$ pat. 3567.

42. Rimdusit $S$, Atthakorn D, Damrongsakkul $S$, Saramas D, Tiptipakorn S. Mechanical, thermal, and water uptake characteristics of woodflour-filled polyvinyl chloride/acrylonitrile butadiene styrene blends. J Appl Polym Sci. 2012;124(2):943-950. DOI:10.1002/app.35130.

43. Belhaneche-Bensemra N, Bedda A. Study of the properties of PVC /ABS blends. Polymer Reactive Processing, Stabilisation and Functionalisation. Italy: Wiley-VCH Verlag $\mathrm{GmbH} ; 2001$.

44. Han Y, Tai ZX, Zhou C, Zhang MY, Zhang HX, Liu $\mathrm{FQ}$. Influence of blend composition on the mechanical properties and morphology of PC/ASA/SAN ternary blends. Polym Bull. 2009;62(6):855-866. DOI:10.1007/s00289-0090057-8.

45. Greco R, Astarita MF, Dong L, Sorrentino A. Polycarbonate/ABS blends: Processability, thermal properties, and mechanical and impact behavior. Adv Polym Technol. 1994;13(4):259-274. DOI: $10.1002 / a d v .1994 .060130402$.

46. Ghazinezami A, Khan WS, Jabbarnia A, Asmatulu R. Impacts of nanoscale inclusions on fire retardancy, thermal stability, and mechanical properties of polymeric PVC nanocomposites. J Therm Eng. 2017;3(4-5):1308-1318. DOI: $10.18186 /$ journal-of-thermal-

engineering. 330150 .

47. Abu-Abdeen M. Static and dynamic mechanical properties of Poly(vinyl chloride) loaded with aluminum oxide nanopowder. Mat. Des. 2012;33:523-528.

DOI: $10.1016 /$ j.matdes.2011.04.059.

48. Saengiet B, Unob F, Srikulkit K. Effect of Styrene-Methyl Methacrylate/Styrene-Butadiene Rubber on Properties of Poly(vinyl chloride). J. Met. Mater. Miner. 2014;24(2):9-13. DOI: $10.14456 / \mathrm{jmmm}$.

49. Zhang $X$, Zhang J. Effect of core-shell structures of acrylonitrile-styrene-acrylate (ASA) terpolymer on the properties of poly(vinyl chloride) (PVC)/ASA blends: Miscibility, toughness, and heat resistance. J. Appl. Polym. Sci. 2018;135(43):46839(1-8). DOI: $10.1002 / a p p .46839$.

50. Miri V, Persyn O, Lefebvre JM, Seguela R. Effect of water absorption on the plastic deformation behavior of nylon 6. Europ Polym J. 2009;45(3):757-762.

DOI: $10.1016 /$ j.eurpolymj.2008.12.008.

51. Pedroso AG, Rosa DS. Effects of the compatibilizer PE-g-GMA on the mechanical, thermal and morphological properties of virgin and reprocessed LDPE/corn starch blends. Polym Adv Technol. 2005;16:310-317. DOI:10.1002/pat.581. 
52. Pilarski JM, Matuana LM. Durability of wood flour-plastic composites exposed to accelerated freeze-thaw cycling. Part I. Rigid PVC matrix. J Vinyl Addtv. Techn. 2005;11(1):1-8. DOI: $10.1002 / \mathrm{vnl} .20029$.
53. Tajvidi M, Haghdan S. Effects of accelerated freeze-thaw cycling on physical and mechanical properties of wood flour/PVC Composites. J Reinf Plastc Comp. 2009;28(15):1841-1846. DOI: $10.1177 / 0731684408090367$. 
KOKCAN YE, Tamer Y. JOTCSA. 2020; 7(3): 635-648.

RESEARCH ARTICLE 